\title{
iTRAQ-based quantitative proteomics analysis of the potential application of secretoneurin gene therapy for cardiac hypertrophy induced by DL-isoproterenol hydrochloride in mice
}

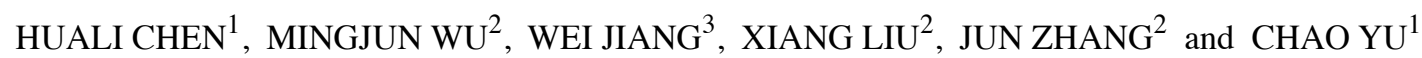 \\ ${ }^{1}$ College of Pharmacy, ${ }^{2}$ Institute of Life Science, Chongqing Medical University, \\ Chongqing 400016; ${ }^{3}$ State Key Laboratory of Biotherapy, Molecular Medicine Research Center, \\ West China Hospital, Sichuan University, Chengdu, Sichuan 610041, P.R. China
}

Received July 9, 2019; Accepted December 17, 2019

DOI: $10.3892 /$ ijmm.2020.4472

\begin{abstract}
A previous study by our group demonstrated a protective role of the neuropeptide secretoneurin (SN) in DL-isoproterenol hydrochloride (ISO)-induced cardiac hypertrophy in mice. To further characterize the molecular mechanism of SN treatment, an isobaric tags for relative and absolute quantification (iTRAQ)-based quantitative proteomic analysis was applied to identify putative target proteins and molecular pathways. An SN expression vector was injected into the myocardial tissues of mice, and the animals were then subcutaneously injected with ISO $(5 \mathrm{mg} / \mathrm{kg} / \mathrm{day})$ for 7 days to induce cardiac hypertrophy. The results of echocardiography and hemodynamic measurements indicated that the function of the heart impaired by ISO treatment was significantly ameliorated via SN gene injection. The investigation of heart proteomics was performed by iTRAQ-based liquid chromatography-tandem mass spectrometry analysis. A total of 2,044 quantified proteins and 15 differentially expressed proteins were associated with SN overexpression in mice with cardiac hypertrophy. Functional enrichment analysis demonstrated that these effects were possibly associated with metabolic processes. A protein-protein interaction network analysis was constructed and the data indicated that apolipoprotein C-III (Apoc3) was associated with the positive effect of $\mathrm{SN}$ on the induction of cardiac hypertrophy in mice. The present study proposed a potential mechanism of SN action on Apoc3 upregulation that may contribute to the amelioration of cardiac hypertrophy. These findings can aid the clinical application of $\mathrm{SN}$ in patients with cardiac hypertrophy.
\end{abstract}

Correspondence to: Dr Chao Yu, College of Pharmacy, Chongqing Medical University, Mailbox 308, 1 Yixueyuan Road, Yuzhong, Chongqing 400016, P.R. China

E-mail: yuchao@cqmu.edu.cn

Key words: secretoneurin, cardiac hypertrophy, isobaric tags for relative and absolute quantification, proteomics, apolipoprotein C-III

\section{Introduction}

Cardiac hypertrophy is characterized by the abnormal enlargement of the heart muscle, which occurs as a result of increased myocyte size and non-muscle cell proliferation $(1,2)$. Cardiac hypertrophy occurs in response to hemodynamic overload and it may predict future coronary artery disease and heart failure (1). Cardiac hypertrophy is a complex process that occurs at the cellular and molecular levels, and involves imbalance of the local autocrine/paracrine network and circulating biologically active mediators (3). To date, several cell-derived factors have been shown to improve cardiac function and have intensively been studied as potential pharmacological targets to prevent and reverse cardiac hypertrophy-associated diseases (3-5).

Secretoneurin (SN) is a 33-amino acid neuropeptide derived from a member of the chromogranin/secretogranin family, secretogranin-II (6). SN is considered a novel biomarker for cardiovascular diseases including ischemic heart disease and heart failure (7-12). In addition, SN demonstrates a protective function in myocardial ischemia/reperfusion injury in experimental animal models $(6,13)$. However, little is known regarding the regulation of $\mathrm{SN}$ in the hypertrophic injury of cardiomyocytes. Our preliminary study demonstrated that SN played a protective role against cardiac hypertrophy induced by DL-isoproterenol hydrochloride (ISO) in mice (14). Nevertheless, the mechanism of the protective action of SN against cardiac hypertrophy remains unclear.

Proteomics is a quantitative analysis of protein expression in biological samples. This method is a powerful screening technology for the global evaluation of protein expression in complex samples. The isobaric tags for relative and absolute quantification (iTRAQ)-labeling method is one of the most reliable techniques that allows the quantitative analysis of proteins based on peptide identification (15). Differential proteomics relies on iTRAQ technology and can reflect the regulatory mechanisms associated with pathological conditions. This approach may be employed in a wide variety of disorders, including cancer, cardiovascular disease and psychiatric illness (16-19). Proteomic profiling has revealed that considerable pathophysiological changes, including 
altered energy metabolism, enhanced protein synthesis, proto-oncogene expression, elevated oxidative stress, occur during cardiac hypertrophy (20-22). However, the majority of these studies have only compared patients with cardiac hypertrophy and healthy subjects $(23,24)$, and the proteomic expression of $\mathrm{SN}$-overexpressing cardiac hypertrophic cells has not been investigated. To the best of our knowledge, the protective mechanism of SN on cardiovascular diseases has not been previously examined using proteomic analysis.

Therefore, in the present study, proteins were labeled by iTRAQ and identified by liquid chromatography-Triple time of flight $\left(\mathrm{LC}^{-T r i p l e T O F}{ }^{\circledR}\right)$ and bioinformatics analyses. The putative target proteins and molecular pathways associated with the protective effect of SN on ISO-induced cardiac hypertrophy in mice were identified. The results of the present study provide information with regard to the possible target proteins and regulatory mechanisms of $\mathrm{SN}$ against cardiac hypertrophy and support the understanding of the potential clinical application of $\mathrm{SN}$ in the treatment of this disease.

\section{Materials and methods}

Materials. The protease inhibitor cocktail used was obtained from Roche Diagnostics GmbH. The iTRAQ Reagent-8plex kit was purchased from AB Sciex. The BCA Protein assay kit was from Thermo Fisher Scientific, Inc., and the anti-apolipoprotein C-III (Apoc3) antibody was purchased from Boster Biological Technology. DL-isoproterenol hydrochloride (ISO; purity $\geq 98.5 \%$ ) was purchased from Sigma-Aldrich; Merck $\mathrm{KGaA}$. The other chemicals used were of analytical grade.

Adenoviral constructs. The SN expression vector was customized from Genechem Co., Ltd., as previously described (14). A signal peptide for the secretion of recombinant SN from transfected cells (ATGGAGTTTGGGCTGAGC TGGCTTTTTCTTGTTGCTGCATTAAGAGGTGTCCAG TCC) and the human SN peptide (ACAAATGAAATAGTG GAGGAACAATATACTCCTCAAAGCCTTGCTACATTG GAATCTGTCTTCCAAGAGCTGGGGAAACTGACAGGA CCAAACAACCAG) were synthesized and cloned into the vector (Ad-SN). A similar recombinant adenovirus expressing green fluorescent protein was used as a negative control (Ad-con). Recombinant adenoviruses were amplified and purified as previously described (25).

Animals. A total of 40 male C57BL/6 mice (age, 8-12 weeks; weight, $22 \pm 2 \mathrm{~g}$ ) were purchased from the Animal Center, Health Sciences Center, Sichuan University. Mice were housed under standard conditions (room temperature, $20 \pm 1^{\circ} \mathrm{C}$; humidity $60 \pm 10 \% ; 12$-h light/dark cycles) and given free access to standard rodent chow and water. The experimental procedures were performed in compliance with the Guide for the Care and Use of Laboratory Animals published by the US National Institute of Health (publication no. 85-23, revised 1985). The protocols were approved by the Animal Care and Use Committee of Sichuan University.

Experimental design. The animals were randomly divided into four groups ( $n=10$ per group) as follows: i) The control group (G1) including animals treated with Ad-con by myocardial injection and with saline by subcutaneous injection; ii) the control group with high SN levels (G2) including animals treated with Ad-SN by myocardial injection and with saline by subcutaneous administration; iii) the cardiac hypertrophy group (G3) including animals treated with Ad-con by myocardial injection and with ISO by subcutaneous administration; iv) the cardiac hypertrophy group with high SN levels (G4), including animals treated with Ad-SN by myocardial injection and with ISO by subcutaneous administration.

In vivo gene delivery and the mouse model of cardiac hypertrophy. The mice were anesthetized with isoflurane (2\%) in oxygen and kept warm at $37^{\circ} \mathrm{C}$. After loss of the righting reflex, the mice were ventilated by intratracheal intubation with a rodent ventilator (Harvard Apparatus). The chest of each mouse was opened to expose the heart and $2 \times 10^{10}$ particles of the Ad-con or Ad-SN (injection volume, $50 \mu \mathrm{l}$ ) were injected into the myocardium at five different sites, as previously described $(26,27)$. Subsequently, the mice received subcutaneous injection of either ISO $(5 \mathrm{mg} / \mathrm{kg} /$ day $)$ or saline into their back for seven days (28). Plasma SN levels were determined by a ultrasensitive electrochemical detection method, which was based on a $\mathrm{Pb}^{2+}$-decorated reduced graphene oxide-tetraethylene pentamine label (12).

\section{Echocardiography and cardiac hemodynamic measurements.} The mice were anesthetized with isoflurane (2\%) in oxygen and kept warm at $37^{\circ} \mathrm{C}$. After loss of the righting reflex, the mice were examined by transthoracic echocardiography and subsequently hemodynamic measurements were performed following a 7-day period administration of adenoviral constructs (29). Transthoracic echocardiography was performed with a GE Vivid 7 (GE Healthcare) and a 12-MHz imaging transducer. The investigator was blinded to the treatments and the complete procedure of the echocardiography was performed by the same person. Following echocardiography, the chest of each animal was opened and the left ventricular function was evaluated by inserting a pressure-volume catheter $1.2 \mathrm{~F}$ transducer $(4.5-\mathrm{mm}$ electrode spacing; serial no. 112B-B057; SCIsense Inc.) into the left ventricle from the apex and positioning it along the cardiac longitudinal axis (29). The signals were recorded by an eight-channel physiological recorder (iWorx 308; iWorx/CB Sciences, Inc.). Following hemodynamic recording, the mice were euthanized by pentobarbital overdose (at least $200 \mathrm{mg} / \mathrm{kg}$, i.p.) (30). After cessation of the heartbeat, the hearts were collected immediately to measure the heart weight and extract the proteins.

Protein sample preparation. The heart tissues of the animals in each group were washed with cold PBS following drug treatment and homogenized in cold PBS at $4^{\circ} \mathrm{C}$. The cells were collected by centrifugation at $1,000 \mathrm{xg}$ for $5 \mathrm{~min}$ at $4^{\circ} \mathrm{C}$ and subsequently lysed in PBS containing protease inhibitor cocktail. The lysates were freeze-thawed three times at $-80^{\circ} \mathrm{C}$ followed by sonication ( $200 \mathrm{~W} ; 30 \mathrm{sec}$ ) on ice and subsequently centrifuged at $11,500 \mathrm{x} \mathrm{g}$ for $20 \mathrm{~min}$ at $4^{\circ} \mathrm{C}$. The supernatant was collected and stored at $-80^{\circ} \mathrm{C}$ prior to further analysis.

iTRAQ labeling. The samples were mixed with cold acetone $(99.5 \%)$ for $2 \mathrm{~h}$ at $-20^{\circ} \mathrm{C}$ and centrifuged at $3,000 \mathrm{xg}$ for $5 \mathrm{~min}$ 
at $4^{\circ} \mathrm{C}$ to precipitate the proteins. Following air-drying, the precipitates were dissolved in dissolution buffer UA $(8 \mathrm{M}$ urea and 0.1 M Tris-HCl; pH 8.5). The concentrations of the proteins were measured using the Bradford method, and the proteins (200 $\mu \mathrm{g}$ per sample) were alkylated and digested with trypsin at $37^{\circ} \mathrm{C}$ for $12 \mathrm{~h}$. The samples were labeled with different isobaric tagging reagents according to the manufacturer's protocol (iTRAQ8plex reagents; AB Sciex). A total of 3 biological replicate samples were merged in one labeling sample, and two samples were prepared for iTRAQ labeling. The peptides from G1-1, G1-2, G2-1, G2-2, G3-1, G3-2, G4-1 and G4-2 were labeled with 115, 116, 117, 118, 113, 114, 119 and 121 iTRAQ reagents, respectively. The iTRAQ reagent-labeled samples were finally pooled.

Strong cation exchange (SCX) chromatography. The pooled samples were added to SCX buffer A (20 mM ammonium formate; $\mathrm{pH}$ 10.0) and mixed well. Following centrifugation at $11,000 \mathrm{x} \mathrm{g}$ for $5 \mathrm{~min}$ at $4{ }^{\circ} \mathrm{C}$, iTRAQ-labeled peptides were separated using a HPLC 2010A system (Shimadzu Corporation) with a Gemini-NX chromatographic column (4.6x250 mm; $5 \mu \mathrm{m} ; 110 \AA$ A Phenomenex; PN:00G-4454-E0). The column was eluted with a linear gradient of $0-20 \%$ SCX buffer A containing $20 \mathrm{mM}$ ammonium formate for $60 \mathrm{~min}$ and subsequently eluted with a gradient of $20-100 \%$ SCX buffer B containing $80 \%$ acetonitrile for an additional $60 \mathrm{~min}$ with a flow rate of $0.8 \mathrm{ml} / \mathrm{min}$ at $25^{\circ} \mathrm{C}$. The fractions were collected at $1 \mathrm{~min}$ intervals and lyophilized in a vacuum concentrator.

Reverse-phase LC-TripleTOF and mass spectrometric analysis. The SCX fractions were resuspended in reverse phase buffer $\mathrm{A}\left(98 \% \mathrm{H}_{2} \mathrm{O}, 2 \%\right.$ acetonitrile, $0.1 \%$ formic acid). The peptides were captured by the reverse phase nano LC Chrom XP C18 column (Chrom XP C18, $350 \mu \mathrm{m}$ x $0.5 \mathrm{~mm}$; $3 \mu \mathrm{m} ; 120 \AA$; Eksigent) and separated using a 60 min linear gradient of buffer $\mathrm{A}$ ( $0.1 \%$ formic acid in $2 \%$ acetonitrile) to buffer B ( $0.1 \%$ formic acid in $98 \%$ acetonitrile) at a flow rate of $300 \mathrm{nl} / \mathrm{min}$. MS was performed in a TripleTOF 5600 instrument (AB Sciex, LLC).The electrospray ionization (ionspray voltage of $2.3 \mathrm{KV}$ ) was used to generate positive ions and the quadrupole time-of-flight mass spectrometer (Q-TOF-MS) was operated in an information-dependent acquisition mode (scan range, $350-1500 \mathrm{~m} / \mathrm{z}$; accumulation time, $0.5 \mathrm{sec}$ ). The peptides were finally selected for MS/MS analyses.

Western blotting. The mouse heart tissues of each group were washed with cold PBS at $4^{\circ} \mathrm{C}$ following drug treatment. The tissues were homogenized and lysed in RIPA buffer (Beyotime Institute of Biotechnology) containing the protein inhibitor cocktail. The lysates were centrifuged at $12,000 \mathrm{x}$ g for $15 \mathrm{~min}$ at $4^{\circ} \mathrm{C}$ to collect the supernatant. The protein concentration was determined by the BCA method. A total of $50 \mu \mathrm{g}$ protein was separated from each sample by SDS-PAGE on a $10 \%$ gel and transferred to polyvinylidene fluoride membranes. The membranes were blocked in 5\% non-fat milk diluted in TBS/T buffer at $4^{\circ} \mathrm{C}$ for $1 \mathrm{~h}$, and then immunoblotted with antibodies against Apoc3 (1:200 in TBS/T buffer; cat. no. PB1097; Boster Biological Technology) or $\beta$-actin $(1: 1,000$ in TBS/T buffer; cat. no. sc-47778; Santa Cruz Biotechnology, Inc.) at $4^{\circ} \mathrm{C}$ overnight. After washing 3 times for $5 \mathrm{~min}$ with TBS/T, the membranes were incubated with HRPconjugated secondary antibodies (1:5,000 diluted in TBS/T; cat. no. ZB-2301 for antirabbit and cat. no. ZB-2305 for antimouse; both OriGene Technologies, Inc.) for $1 \mathrm{~h}$ at room temperature. The bands were visualized with enhanced chemiluminescence reagents (Merck KGaA) using Image Lab software (version 4.0; Bio-Rad Laboratories, Inc.).

Dataprocessing andanalysis. The MS raw data were accessed at www.iprox.org/page/PSV023.html;?url=1561949914798JAZl with the following password: [KTuX]. The MS raw data files were uploaded into the PeakView software (version 1.2; AB Sciex, LLC) for peak detection, generation of peak lists of mass error corrected peptides and database searches. Protein identification and quantification were performed with ProteinPilot software (version 4.0; AB SCIEX) against the uniprot-taxonomy_10090 mouse protein database (www. uniprot.org/uniprot/?query=taxonomy:10090). All common fixed and variable modifications of proteins were considered. iTRAQ 8 plex (Peptide Labeled) was selected as the quantitation mode. A total of three missed cleavages were allowed and the enzyme specificity was selected as 'trypsin'. Mass tolerance for the initial search was selected as ' $5 \mathrm{ppm}$ ' and the $\mathrm{MS} / \mathrm{MS}$ tolerance was set to $0.1 \mathrm{Da}$. The data were estimated using automatic decoy searching for false discovery rate (FDR) analysis. The relative expression levels of the proteins at different treatment protocols were calculated using G3 as the reference. The proteins that met the following criteria were selected for further analysis: i) Significantly changed expression (fold-change $\geq 1.5$ fold or $\leq 0.667$ fold vs. control; $\mathrm{P}<0.05$ ); ii) a minimum of three peptides with $95 \%$ confidence; and iii) $1 \%$ global FDR. The bioinformatics analysis ensured that all identified protein accessions were submitted to the Database for annotation, visualization and integrated discovery (DAVID; version 6.8; http://david.abcc.ncifcrf.gov). Subsequently, the default matched organism was selected as 'background to do' analysis. The Gene Ontology (GO; geneontology.org) and Kyoto Encyclopedia of Genes and Genomes (KEGG; www. genome.jp/kegg) reports from DAVID were downloaded to draw charts using specific in-house Perl and R scripts. The accession of DEPs was submitted to the Search Tool for the Retrieval of Interacting Genes/Proteins (STRING; version 10; www.string-db.org) for the protein-protein interaction (PPI) files. Subsequently, the PPI files and the protein expression file were imported to Cytoscape software (version 3.2.1; www. cytoscape.org) to construct and display the PPT network.

Statistical analysis. The results are presented as the mean \pm SEM $(n=6)$. The comparisons were performed using GraphPad Prism software (version 5; GraphPad Software, Inc.) with unpaired Student's t-test and the one-way ANOVA followed by the Tukey's post hoc test. $\mathrm{P}<0.05$ was considered to indicate a statistically significant difference.

\section{Results}

SN gene overexpression improves the left ventricular hypertrophy and dysfunction induced by ISO. The echocardiography and cardiac hemodynamic measurements were performed following ISO treatment in order to evaluate the cardiac 
A
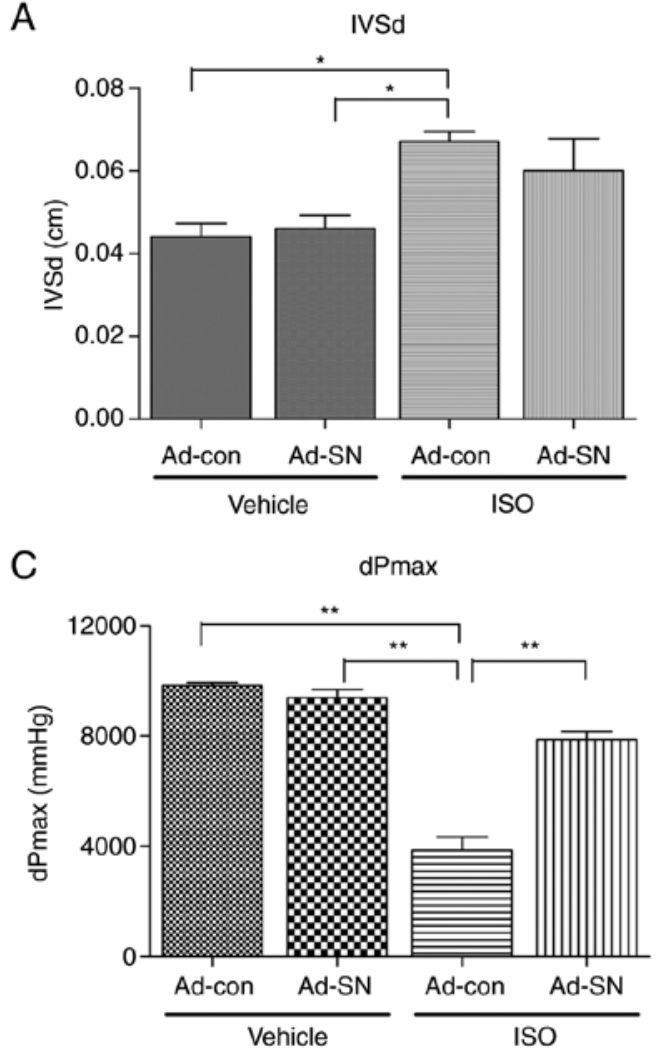

B

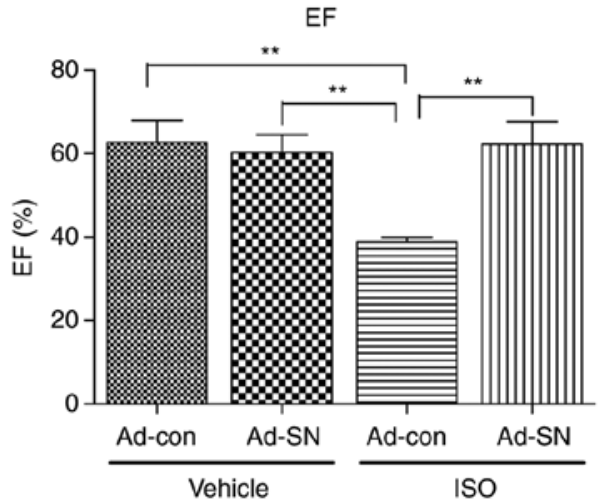

D

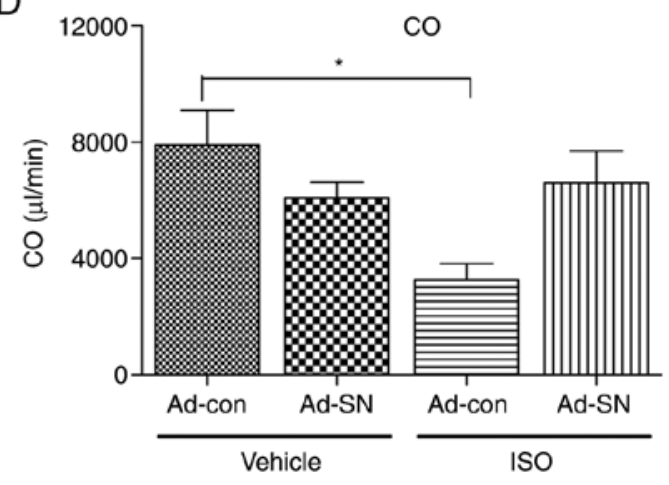

Figure 1. Echocardiography and hemodynamic measurements. G1 mice received Ad-con intramyocardial injection and vehicle subcutaneous injection, G2 mice received Ad-SN intramyocardial injection and vehicle subcutaneous injection, G3 mice received Ad-con intramyocardial injection and ISO subcutaneous injection and G4 mice received Ad-SN intramyocardial injection and ISO subcutaneous injection. (A) IVSd of mice in G1, G2, G3 and G4; (B) EF (Teich)\% of mice in G1, G2, G3 and G4; (C) dPmax of mice in G1, G2, G3 and G4; (D) CO of mice in G1, G2, G3 and G4. The data are presented as the mean \pm SEM (n=6/group). ${ }^{*} \mathrm{P}<0.05$ and ${ }^{* *} \mathrm{P}<0.01$. G1-4, groups 1-4; Ad, adenovirus; SN, secretoneurin; ISO, isoprenaline; IVSd, left ventricle (LV) end systolic diameter; EF (Teich)\%, ejection fraction calculated by the Teichholz method; dPmax, maximal value of the first derivative of LV pressure; CO, cardiac output.

protective effect of SN (Fig. 1). Following a 7-day period of treatment with ISO, the mice that received Ad-con injections exhibited significant cardiac hypertrophy and cardiac dysfunction compared with the vehicle-treated Ad-con mice. The plasma SN levels were detected by electrochemical detection methods. Compared with the mice that received Ad-con injections, significantly higher plasma SN levels were observed in mice receiving Ad-SN injections (both $\mathrm{P}<0.01$; Table I). ISO treatment also significantly increased plasma $\mathrm{SN}$ levels in the mice receiving Ad-con injections $(\mathrm{P}<0.01$; Table I), compared with vehicle-treated mice receiving Ad-con injections. The data indicated a higher left ventricle (LV) end systolic diameter (IVSd, $\mathrm{P}<0.05$; Fig. 1A) and a lower ejection fraction, as estimated by the Teichholz method (EF, $\mathrm{P}<0.01$; Fig. 1B). In addition, the maximal values of the first derivative of $\mathrm{LV}$ pressure (dPmax, $\mathrm{P}<0.01$; Fig. $1 \mathrm{C}$ ) and the cardiac output $(\mathrm{CO}$, $\mathrm{P}<0.05$; Fig. 1D) were noted. However, $\mathrm{SN}$ gene therapy partly restored these levels to approximately $10.4 \%(\mathrm{P}>0.05)$ lower in IVSd, and $60.8 \%(\mathrm{P}<0.01), 104.5 \%(\mathrm{P}<0.01)$ and $101.1 \%$ $(\mathrm{P}>0.05)$ higher in $\mathrm{EF}, \mathrm{dPmax}$ and $\mathrm{CO}$, respectively compared with the corresponding levels noted in ISO-treated Ad-con mice. The results demonstrated that $\mathrm{SN}$ played a protective role in ISO-induced cardiac hypertrophy.

Identification of differentially expressed proteins following SN gene injection in the ISO-induced cardiac hypertrophy mouse model. Using iTRAQ coupled with LC TripleTOF, the present study identified 2,044 proteins with a 1\% FDR from 19,729 distinct peptides derived from 106,837 spectra. A 1.5-fold-change of expression cut-off value for 1,217 proteins was used as the cut-off point. A total of 15 proteins indicated a significant change $(\mathrm{P}<0.05)$ in their expression levels between the G2 and G1 groups, whereas 41 proteins exhibited a significant change $(\mathrm{P}<0.05)$ in their expression levels between the $\mathrm{G} 3$ and G1 groups. A total of 24 proteins exhibited a significant change $(\mathrm{P}<0.05)$ in their expression levels between the $\mathrm{G} 4$ and the G3 groups (Fig. 2). A total of 12 proteins exhibited common upregulated expression levels and three proteins demonstrated common downregulated expression levels following SN gene therapy compared with those of the control group (G2 vs. G1; Fig. 2). In cardiac hypertrophic animals (G3), a higher number of common proteins exhibited differentially expression levels (9 upregulated and 32 downregulated) compared with the expression levels noted in the control group (G1; Fig. 2). Moreover, following SN gene therapy, 24 proteins indicated upregulated expression compared with the corresponding proteins of the cardiac hypertrophic group (G4 vs. G3; Fig. 2). A total of 32 downregulated proteins were identified in the cardiac hypertrophic group and 15 of them exhibited upregulated expression following SN gene therapy. These proteins did not exhibit a change between the G1 and G2 groups (Fig. 3 and Table II).

GO classification of differentially expressed proteins. To further understand the function and role of $\mathrm{SN}$-associated 
Table I. Plasma SN levels determined by electrochemical methods in vehicle- or ISO-treated mice receiving Ad-con or Ad-SN intramyocardial injections.

\begin{tabular}{lc} 
Group & Plasma SN level (ng/ml) \\
\hline 1 & $3.1 \pm 0.4$ \\
2 & $8.8 \pm 0.4^{\mathrm{a}}$ \\
3 & $7.4 \pm 0.5^{\mathrm{a}}$ \\
4 & $13.0 \pm 0.5^{\mathrm{b}, \mathrm{c}}$ \\
\hline
\end{tabular}

SN, secretoneurin; G1-4, groups 1-4. The data are presented as the mean \pm SEM. $(n=4) .{ }^{a} \mathrm{P}<0.01$ vs. $\mathrm{G} 1{ }^{\mathrm{b}} \mathrm{P}<0.01$ vs. $\mathrm{G} 2{ }^{\circ}{ }^{\mathrm{c}} \mathrm{P}<0.01$ vs. $\mathrm{G} 3$.

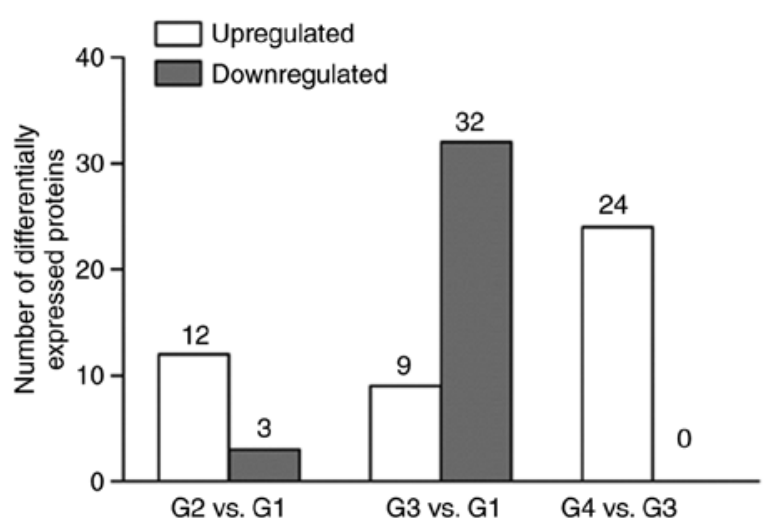

Figure 2. Differentially expressed protein counts detected by isobaric tags for relative and absolute quantification coupled with a liquid chromatography-time of flight-based proteomic technology $(n=6)$. G1 mice received Ad-con intramyocardial injection and vehicle subcutaneous injection, G2 mice received Ad-SN intramyocardial injection and vehicle subcutaneous injection, G3 mice received Ad-con intramyocardial injection and ISO subcutaneous injection and G4 mice received Ad-SN intramyocardial injection and ISO subcutaneous injection. G1-4, groups 1-4; Ad, adenovirus; $\mathrm{SN}$, secretoneurin; ISO, isoprenaline.

proteins, GO and pathway enrichment analysis were performed using DAVID. The top ten significantly enriched biological processes were identified, including the cellular component and molecular function terms (Fig. 4).

Following comparison of the biological process $\mathrm{GO}$ terms corresponding to the differentially expressed proteins of the G3 and G1 groups, seven terms were closely associated with cardiac hypertrophy and cardiac injury ('striated muscle contraction', 'regulation of the force of heart contraction', 'regulation of heart contraction', 'muscle contraction', 'cardiac muscle contraction', 'heart contraction' and 'heart process'). The other three significantly enriched biological processes were associated with the metabolic process (Fig. 4B). The comparison of the differentially expressed proteins of the G4 and G3 groups demonstrated that all the significantly enriched biological processes were associated with metabolic processes (Fig. 4C). With regard to the cellular component, the top two terms of the differentially expressed proteins were compared between the G3 and G1 and the G4 and G3 groups. These terms were involved in the cytoplasmic and the mitochondrial function processes (Fig. 4B and C).
The comparison of the G2 and G1 groups revealed no significant differences in the enriched molecular function terms of the differentially expressed proteins (Fig. 4A). The top three terms in the differentially expressed proteins of the G3 and the G1 groups were 'coenzyme binding', 'cofactor binding' and 'oxidoreductase activity acting on the $\mathrm{CH}-\mathrm{OH}$ group of donors' (Fig. 4B). The top three terms in the differentially expressed proteins of the G4 and the G3 groups were 'oxidoreductase activity', 'catalytic activity' and 'poly(A) RNA binding' (Fig. 4C).

Metabolic pathways involved in SN-mediated protection against cardiac hypertrophy in mice. KEGG pathway analysis was used to identify the metabolic pathways of the differentially expressed proteins. The 41 differentially expressed proteins of the G3 and the G1 groups were significantly enriched in ten signaling pathways, with 'cardiac muscle contraction', 'adrenergic signaling in cardiomyocytes' and 'metabolic pathways' as the top three enriched pathways (Fig. 5A). The 24 differentially expressed proteins derived from the comparison of the G4 and G3 groups were significantly enriched in 24 signaling pathways, with 'carbon metabolism', 'biosynthesis of antibiotics' and 'metabolic pathways' as the top three enriched pathways (Fig. 5B). The comparison of the differentially expressed proteins of the G2 and G1 groups did not reveal enriched pathways.

Furthermore, a protein-protein interaction network analysis of SN was performed using the STRING website and Cytoscape software (Fig. 6). Among the network of the protein-protein interaction surrounding SN, the differentially expressed proteins were identified by iTRAQ as follows: Hydroxyacyl-CoA dehydrogenase trifunctional multienzyme complex subunit $\beta$ (Hadhb), apolipoprotein C-III (Apoc3) and myosin heavy polypeptide 7 cardiac muscle $\beta$ (Myh7).

SN influences cardiac hypertrophy by altering Apoc3 levels. For quantitative validation of candidate proteins, western blot analysis of Apoc3 was performed. The protein expression levels of Apoc3 were significantly decreased in the cardiac hypertrophy animals (Fig. 7; P<0.01). However, the comparison of the cardiac hypertrophic group with the control group demonstrated that SN gene therapy effectively induced Apoc3 expression by $41.8 \%$ (Fig. 7 ; $\mathrm{P}<0.05$ ). The results suggested that $\mathrm{SN}$ increased Apoc3 expression levels in the hypertrophic heart tissues.

\section{Discussion}

Various forms of ventricular pressure overload can cause cardiac hypertrophy, which is an imbalance in cardiac homeostasis (31). In cardiac hypertrophy, catecholamine levels are increased and adrenergic stimulation occurs (32). During the development of this condition, several endogenous factors are involved $(3,33)$. SN was initially discovered as a regulator of neurogenic inflammation (34). However, subsequent studies demonstrated that it could act as a potential protector against cardiovascular events $(6,13,35)$. SN plays a protective role in myocardial ischemia and heart failure $(36,37)$ by inducing angiogenesis and postnatal vasculogenesis $(13,38)$. However, to the best of our knowledge, the regulation of $\mathrm{SN}$ in cardiac 
Table II. List of the SN-related significantly differential proteins $(n=6){ }^{a}{ }^{a}$

Fold-change

Protein name

Protein ID

Gene

$\mathrm{G} 2 / \mathrm{G} 1 \quad \mathrm{G} 3 / \mathrm{G} 1$

G4/G3

Oxoglutarate dehydrogenase like

$\Delta(3,5)-\Delta(2,4)$-dienoyl-CoA isomerase, mitochondrial

Myosin light chain 3

Myosin regulatory light chain 2, ventricular/cardiac

muscle isoform

Lipoamide acyltransferase component of branched-chain $\alpha$-keto acid dehydrogenase complex, mitochondrial

Isocitrate dehydrogenase [NADP], mitochondrial

Cardiac phospholamban

Hydroxyacyl-coenzyme A dehydrogenase, mitochondrial

Creatine kinase S-type, mitochondrial

$\begin{array}{ll}\text { B2RXT3_MOUSE } & \text { Ogdhl } \\ \text { ECH1_MOUSE } & \text { Ech1 } \\ \text { MYL3_MOUSE } & \text { Myl3 } \\ \text { MLRV_MOUSE } & \text { Myl2 }\end{array}$

$\begin{array}{lll}1.01 \pm 0.15 & 0.66 \pm 0.03 & 1.73 \pm 0.08\end{array}$

$\begin{array}{lll}0.93 \pm 0.06 & 0.61 \pm 0.03 & 1.57 \pm 0.09\end{array}$

$\begin{array}{lll}0.97 \pm 0.04 & 0.65 \pm 0.13 & 2.21 \pm 0.38\end{array}$

$\begin{array}{lllll}\text { MLRV_MOUSE } & \text { Myl2 } & 0.89 \pm 0.03 & 0.59 \pm 0.12 & 1.57 \pm 0.39\end{array}$

D- $\beta$-hydroxybutyrate dehydrogenase, mitochondrial

Trifunctional enzyme subunit $\beta$, mitochondrial

Myosin, heavy polypeptide 7, cardiac muscle, $\beta$

Apolipoprotein C-III

Fatty acid binding protein 3 , muscle and heart

Cytochrome $\mathrm{c}$ oxidase subunit 6A, mitochondrial

$\begin{array}{llrll}\text { ODB2_MOUSE } & \text { Dbt } & 0.99 \pm 0.02 & 0.58 \pm 0.04 & 1.52 \pm 0.12 \\ & & & & \\ \text { IDHP_MOUSE } & \text { Idh2 } & 1.04 \pm 0.08 & 0.53 \pm 0.03 & 1.95 \pm 0.02 \\ \text { PPLA_MOUSE } & \text { Pln } & 1.01 \pm 0.12 & 0.64 \pm 0.04 & 1.71 \pm 0.06 \\ \text { HCDH_MOUSE } & \text { Hadh } & 1.15 \pm 0.18 & 0.58 \pm 0.02 & 1.82 \pm 0.08 \\ \text { KCRS_MOUSE } & \text { Ckmt2 } & 1.14 \pm 0.03 & 0.65 \pm 0.01 & 1.97 \pm 0.36 \\ \text { BDH_MOUSE } & \text { Bdh1 } & 1.25 \pm 0.09 & 0.66 \pm 0.03 & 1.81 \pm 0.17 \\ \text { ECHB_MOUSE } & \text { Hadhb } & 1.061 \pm 0.12 & 0.63 \pm 0.05 & 1.59 \pm 0.18 \\ \text { B2RXX9_MOUSE } & \text { Myh7 } & 0.63 \pm 0.21 & 0.39 \pm 0.06 & 2.48 \pm 0.39 \\ \text { E9QP56_MOUSE } & \text { Apoc3 } & 0.81 \pm 0.13 & 0.64 \pm 0.13 & 1.78 \pm 0.39 \\ \text { Q5EBJ0_MOUSE } & \text { Fabp3 } & 1.03 \pm 0.15 & 0.58 \pm 0.03 & 1.83 \pm 0.14 \\ \text { Q8R2L0_MOUSE } & \text { Cox6a2 } & 0.89 \pm 0.04 & 0.56 \pm 0.09 & 2.11 \pm 0.45\end{array}$

${ }^{a}$ The proteins were significantly different with regard to the comparison of the cardiac hypertrophy (G3) and the control (G1) groups and with regard to the comparison of the SN gene therapy (G4) with the cardiac hypertrophy (G3) groups. The alteration trends of these proteins were opposite following the two different comparisons. SN, secretoneurin; G1-4, groups 1-4.

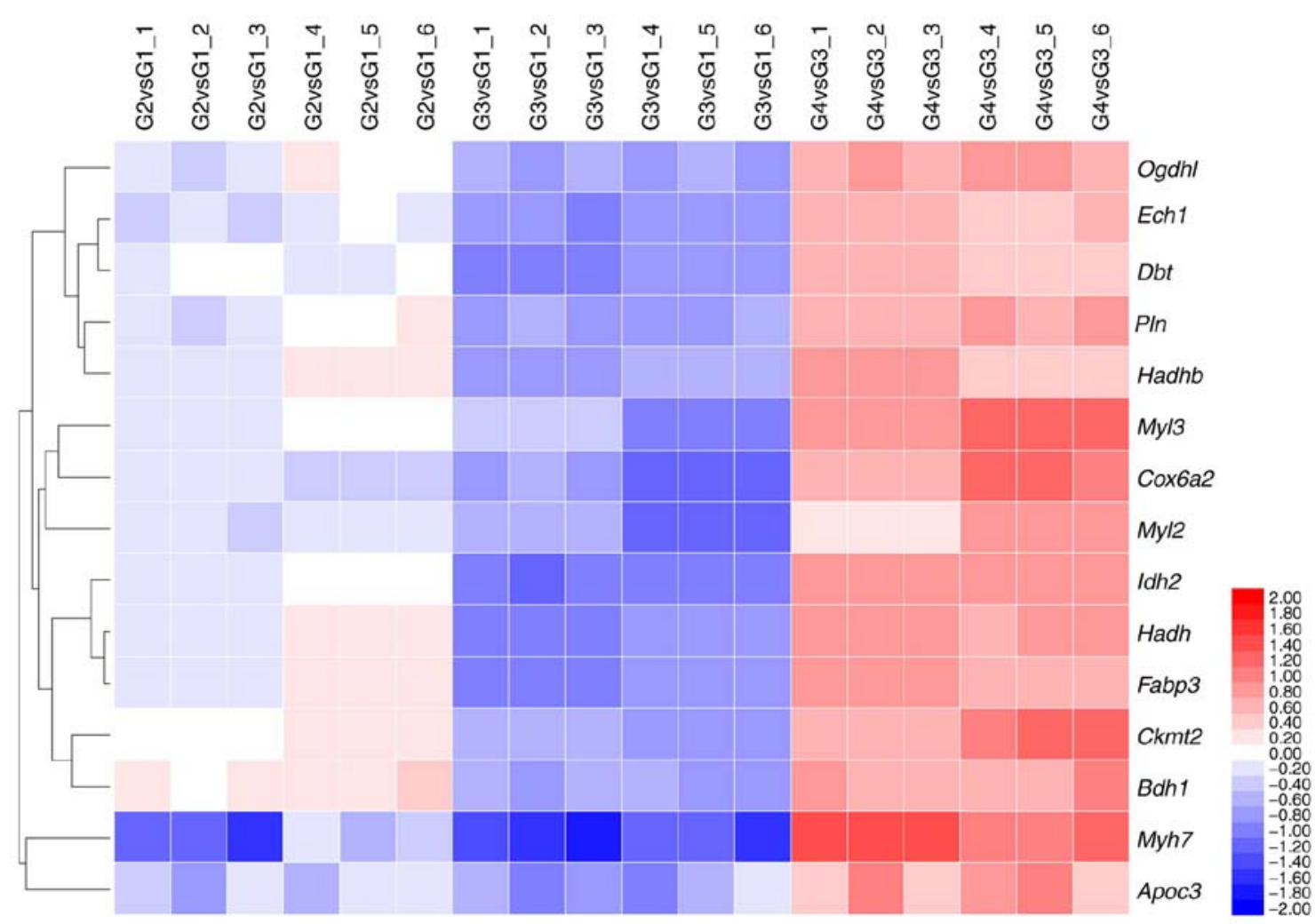

Figure 3. Differentially expressed proteins were detected by isobaric tags for relative and absolute quantification coupled with a liquid chromatography-time of flight-based proteomic technology and heatmaps were constructed. G1 mice received Ad-con intramyocardial injection and vehicle subcutaneous injection, G2 mice received Ad-SN intramyocardial injection and vehicle subcutaneous injection, G3 mice received Ad-con intramyocardial injection and ISO subcutaneous injection and G4 mice received Ad-SN intramyocardial injection and ISO subcutaneous injection. (n=6). G1-4, groups 1-4; Ad, adenovirus; $\mathrm{SN}$, secretoneurin. 


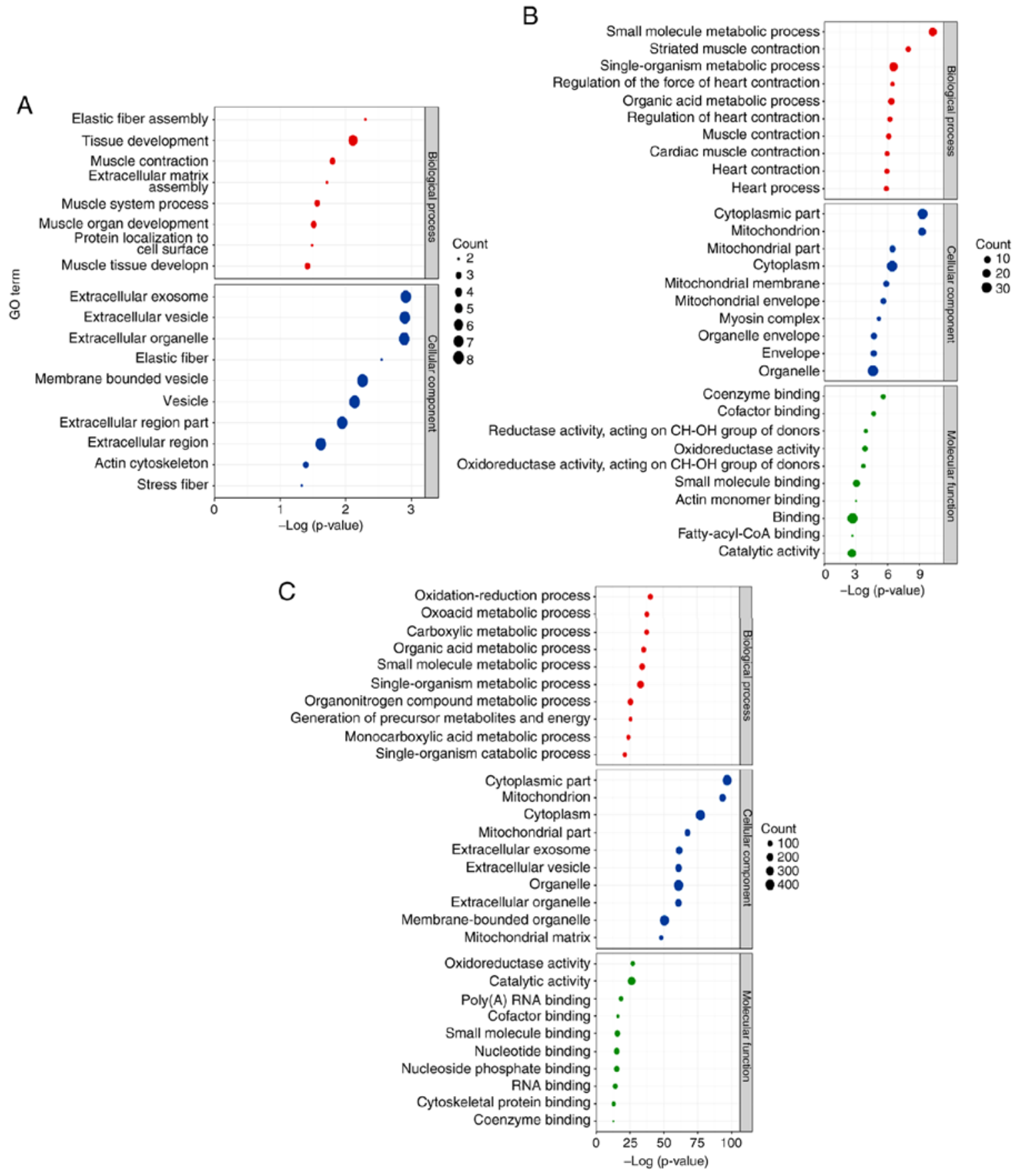

Figure 4. GO analysis of differentially expressed proteins (n=6). (A) GO analysis of differentially expressed proteins following comparison of G2 and G1 groups (G2 vs. G1). (B) GO analysis of differentially expressed proteins following comparison of G3 and G1 groups (G3 vs. G1). (C) GO analysis of differentially expressed proteins following comparison of G4 and G3 groups (G4 vs. G3). GO, Gene Ontology; G1-4, groups 1-4.

hypertrophy has not been previously investigated. In the preliminary study conducted by our research group, $\mathrm{SN}$ played a protective role on cardiac hypertrophy induced by ISO in mice. SN gene therapy resulted in a significant improvement in cardiac hypertrophy and cardiac dysfunction (14). However, the mechanism of the protective role of SN on cardiac hypertrophy was not fully elucidated.

iTRAQ quantitative proteomic technology has been previously used to reveal the mechanisms of diseases (39) or drug treatment $(40,41)$. However, to the best of our knowledge, no studies focusing on the protective role of SN on cardiac hypertrophy have been previously reported. Therefore, in the present study, iTRAQ coupled with a LC-TripleTOF-based proteomic technology was used to identify and quantify the differentially expressed candidate proteins in response to $\mathrm{SN}$-mediated inhibition of cardiac hypertrophy induced by ISO for the first time. A total of 41 differentially expressed proteins were observed between hypertrophic and non-hypertrophic heart tissues in mice (G3 vs. G1). A total of 9 proteins were upregulated, whereas 32 proteins were downregulated. Following SN gene therapy, 24 proteins exhibited upregulated expression compared with those noted in the hypertrophic heart with the control gene therapy (G4 vs. G3). In iTRAQ based-comparative proteomic studies, more upregulated differentially expressed 


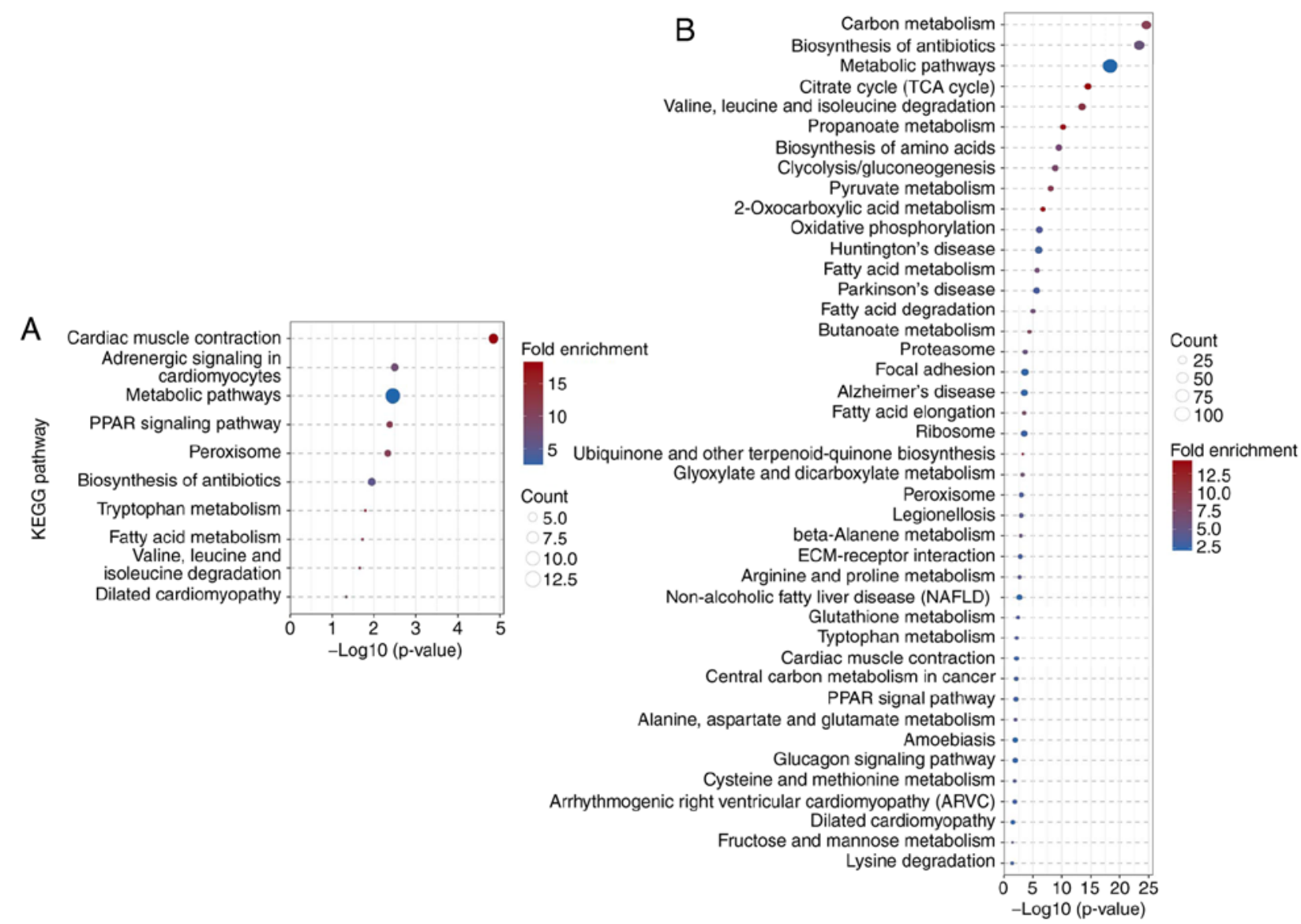

Figure 5. KEGG analysis of differentially expressed proteins (n=6). (A) KEGG analysis of differentially expressed proteins following comparison of G3 and G1 groups (G3 vs. G1). (B) KEGG analysis of differentially expressed proteins following comparison of G4 and G3 groups (G4 vs. G3). KEGG, Kyoto Encyclopedia of Genes and Genomes; G1-4, groups 1-4.

proteins were found than down-regulated ones (42-45). In the majority of the studies using similar quantitative proteomic techniques, the criteria for selecting differential expression protein were set as 'fold-change $\geq 1.2$ fold or $\leq 0.83$ fold vs. control' $(39,40)$. Whereas, in the present study, the criteria were set as 'fold change $\geq 1.5$ fold or $\leq 0.667$ fold vs. control; $\mathrm{P}<0.05$ '. Higher criteria for selecting differential expressed proteins were selected, as this approach was likely to filter out a large number of downregulated differential expressed proteins whose changes were smaller than the criteria. Therefore, it was not difficult to infer that all differentially expressed proteins were upregulated in the results. A total of 15 out of 32 downregulated proteins (G3 vs. G1 groups) were closely associated with the protective effects of SN gene therapy on cardiac hypertrophy in mice.

GO analysis of differentially expressed proteins indicated that the significantly enriched biological processes were cellular component and molecular function terms. The GO analysis of the differentially expressed proteins resulting from the comparison of the hypertrophic and the non-hypertrophic heart tissues (G3 vs. G1) indicated the top ten significantly enriched biological processes, of which seven terms were closely associated with cardiac hypertrophy and cardiac injury. This result was expected, since the samples from the hypertrophic hearts were pooled. The other three terms were associated with metabolic processes, as myocardial metabolic impairment is a major feature of cardiac hypertrophy and heart failure (46-48). The effect of SN gene therapy on the hypertrophic heart tissues (comparison of G4 and G3 groups) resulted in the identification of significantly enriched biological process terms that were associated with the metabolic process. These results indicated that $\mathrm{SN}$ played a protective role in cardiac hypertrophy by regulating the metabolic process in cardiomyocytes. KEGG analysis indicated similar results to those derived from the GO analysis, suggesting that the differentially expressed proteins in the hypertrophic heart were significantly associated with cardiac muscle contraction, adrenergic signaling in cardiomyocytes and metabolic pathways, whereas following SN gene therapy, the differentially expressed proteins were all associated with metabolic pathways. These results suggested that the metabolic pathways played a critical role in the protective effect of SN in ISO-induced cardiac hypertrophy in mice.

To further investigate the mechanism of SN regulation in the hypertrophic heart, a protein-protein interacting network analysis of $\mathrm{SN}$ was performed. The network of protein-protein interaction surrounding SN highlighted the identification of three proteins in 50 candidate targets by iTRAQ, which were considered to be closely associated with the protective role of SN-gene therapy on cardiac hypertrophy in mice. These three proteins were Hadhb, Apoc3 and Myh7. Myh7 is 


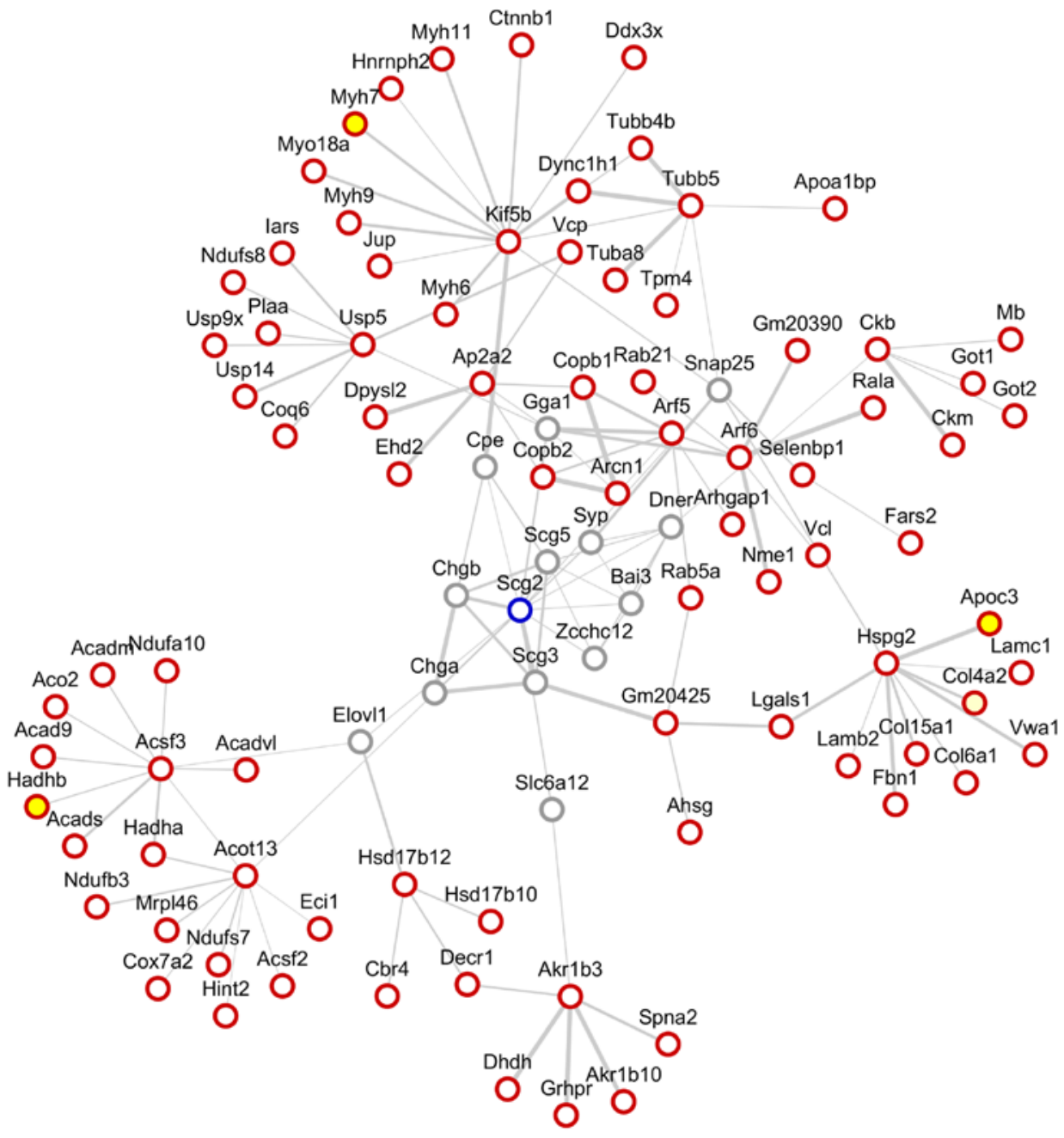

Figure 6. Highly interconnected protein networks surrounding SN. Red is indicative of differentially expressed proteins. Gray is indicative of non-differentially expressed proteins. Yellow is indicative of differentially expressed proteins in the 15 candidate proteins presented in Table I. SN, secretoneurin.

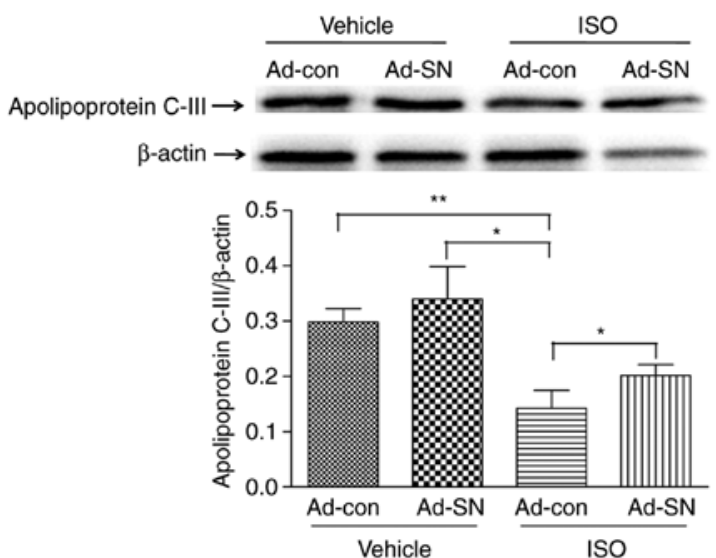

Figure 7. Expression levels of Apoc3 in cardiac ventricles of vehicle- or ISO-treated mice that were administered Ad-con or Ad-SN intramyocardial injections. The protein expression was determined by western blotting. Ad-con mice were treated by intramyocardial injection with Ad-con, whereas Ad-SN mice were treated by intramyocardial injection with Ad-SN. The data are presented as the mean $\pm \operatorname{SEM}(\mathrm{n}=6){ }^{*} \mathrm{P}<0.05$ and ${ }^{* * *} \mathrm{P}<0.01$, as indicated. Apoc3, apolipoprotein C-III; ISO, isoprenaline; Ad, adenovirus; $\mathrm{SN}$, secretoneurin.

a slow molecular ATPase involved in muscle contraction (49) and several studies have demonstrated that the gene encoding for this protein is mutated in cardiac hypertrophy, resulting in altered protein expression levels (50-52). Hadhb is involved in the pathway of fatty acid $\beta$-oxidation. To the best of our knowledge, the role of this protein in cardiac hypertrophy has not yet been demonstrated. Apoc3 is associated with high levels of triglycerides and remnant cholesterol. Apoc3 inhibits the hydrolysis of triglyceride-rich lipoproteins by lipoprotein lipase (53) and reduces the uptake of triglyceride-rich lipoproteins by the liver, thereby increasing plasma triglyceride levels $(54,55)$. Apoc3 has been proposed as a potential target for reducing residual cardiovascular risk (56-58). Several studies have demonstrated that the role of Apoc3 in ischemic cardiovascular disease is associated with its ability to impair plasma lipoprotein metabolism, which in turn leads to increased triacylglyceraldehyde levels (56-58). In the present study, Apoc3 was identified as a major protein involved in the $\mathrm{SN}$-mediated inhibition of cardiac hypertrophy. These data were derived by iTRAQ and were further validated by western blotting, suggesting that Apoc3 was indeed involved in the protection of SN against cardiac hypertrophy. The results indicated significantly reduced expression levels of Apoc3 in hypertrophic heart tissues compared with those noted in non-hypertrophic heart tissues. However, the expression levels of Apoc3 were significantly increased 
following SN gene therapy. These results indicated the SN protective role against cardiac hypertrophy by increasing the levels of Apoc3 expression. However, although the expression of Apoc3 was altered, the limitation of present study was that Apoc3 was not knocked down to confirm its role in protecting cardiac hypertrophy by SN. Further follow-up studies are undergoing to provide additional information on the protective mechanism of Apoc3 on cardiac hypertrophy by SN.

The present study utilized comparative proteomic analysis following iTRAQ labeling to identify 15 differentially expressed proteins in cardiac hypertrophy and $\mathrm{SN}$-overexpressed cardiac hypertrophy groups. Moreover, the protective role of SN on cardiac hypertrophy was revealed. The majority of these proteins were involved in cardiac muscle contraction and metabolism pathways. A protein-protein interaction network analysis of SN demonstrated that of the 15 differentially expressed proteins, Hadhb, Apoc3 and Myh7 were associated with the function of $\mathrm{SN}$-gene overexpression in cardiac hypertrophy. Western blotting indicated that Apoc3 levels were downregulated in hypertrophic heart tissues, whereas they were upregulated follwing SN gene therapy. Further validation of these putative target proteins and pathways is essential in future studies in order to improve our understanding of the regulatory mechanisms of SN in cardiac hypertrophy.

\section{Acknowledgements}

The authors would like to thank Mr. Hong Yu (Shanghai Shengzi biological technology Co., Ltd., Shanghai, China) for assistance with the bioinformatics analysis.

\section{Funding}

The present study was supported by the National Natural Science Foundation of China (grant nos. 81400212 and 81370403), Chongqing Basic and Frontier Research Project (grant nos.CSTC2015jcyjBX0053 and CSTC2018jcyjAX0126), Chongqing Precision Medical Key Technology Research and Development and Demonstration Projects (grant no. cstc2016shms-ztzx0042), and the Funds for Outstanding Young Scholars in Chongqing Medical University (grant no. CYYQ201309).

\section{Availability of data and materials}

The datasets used and/or analyzed during the current study are available from the corresponding author on reasonable request. The MS raw data can be accessed at https://iprox. org/page/SSV024.html;url=1574211720733k2Jh with password [7DSA].

\section{Authors' contributions}

HC performed the mouse model study and contributed to manuscript writing. MW performed the iTRAQ labeling and the LC-MS/MS analysis. WJ performed the echocardiography and cardiac hemodynamic measurements. XL performed the bioinformatics analysis. JZ prepared the protein samples and performed the western blotting. CY designed the study and contributed to manuscript writing. All authors read and approved the final manuscript.

\section{Ethics approval and consent to participate}

The protocols were approved by the Animal Care and Use Committee of Sichuan University.

\section{Patient consent for publication}

Not applicable.

\section{Competing interests}

The authors declare that they have no competing interests.

\section{References}

1. Frey N and Olson EN: Cardiac hypertrophy: The good, the bad, and the ugly. Annu Rev Physiol 65: 45-79, 2003.

2. Oparil S: Pathogenesis of ventricular hypertrophy. J Am Coll Cardiol 5: 57B-65B, 1985.

3. Cingolani HE, Ennis IL, Aiello EA and Perez NG: Role of autocrine/paracrine mechanisms in response to myocardial strain. Pflugers Arch 462: 29-38, 2011.

4. Doroudgar S and Glembotski CC: The cardiokine story unfolds: Ischemic stress-induced protein secretion in the heart. Trends Mol Med 17: 207-214, 2011.

5. Finckenberg P and Mervaala E: The cardiokine story unfolds: Ischemic stress-induced protein secretion in the heart. J Hypertens 28 (Suppl): S33-S38, 2010.

6. Albrecht-Schgoer K, Schgoer W, Holfeld J, Theurl M, Wiedemann D, Steger C, Gupta R, Semsroth S, Fischer-Colbrie R, Beer AG, et al: The angiogenic factor secretoneurin induces coronary angiogenesis in a model of myocardial infarction by stimulation of vascular endothelial growth factor signaling in endothelial cells. Circulation 126: 2491-2501, 2012.

7. Pertl C, Kaufmann W, Amann R, Heinemann A, Ebeleseder K, Polansky R, Saria A and Kim S: Secretoneurin, a novel neuropeptide, in the human dental pulp. Arch Oral Biol 43: 361-365, 1998.

8. Ceconi C, Ferrari R, Bachetti T, Opasich C, Volterrani M, Colombo B, Parrinello $\mathrm{G}$ and Corti A: Chromogranin A in heart failure; a novel neurohumoral factor and a predictor for mortality. Eur Heart J 23: 967-974, 2002.

9. RosjoH, Masson S,Latini R, Flyvbjerg A,Milani V,La Rovere MT, Revera M, Mezzani A, Tognoni G, Tavazzi L, et al: Prognostic value of chromogranin A in chronic heart failure: Data from the GISSI-Heart Failure trial. Eur J Heart Fail 12: 549-556, 2010.

10. Rosjo H, Husberg C, Dahl MB, Stridsberg M, Sjaastad I, Finsen AV, Carlson CR, Oie E, Omland T and Christensen G: Chromogranin B in heart failure: A putative cardiac biomarker expressed in the failing myocardium. Circ Heart Fail 3: 503-511, 2010.

11. Jansson AM, Rosjo H, Omland T, Karlsson T, Hartford M, Flyvbjerg A and Caidahl K: Prognostic value of circulating chromogranin A levels in acute coronary syndromes. Eur Heart J 30: 25-32, 2009.

12. Yuan G, Chen H, Xia C, Gao L and Yu C: Ultrasensitive electrochemical detection of secretoneurin based on $\mathrm{Pb}(2+)$-decorated reduced graphene oxide-tetraethylene pentamine as a label. Biosens Bioelectron 69: 95-99, 2015.

13. Rosjo H, Stridsberg M, Florholmen G, Stenslokken KO, Ottesen AH, Sjaastad I, Husberg C, Dahl MB, Oie E, Louch WE, et al: Secretogranin II; a protein increased in the myocardium and circulation in heart failure with cardioprotective properties. PLoS One 7: e37401, 2012.

14. Chen HL, Liu Y, Jiang W, Wang XX, Yuan GL, Zhao YL and Yu C: Secretoneurin suppresses cardiac hypertrophy through suppression of oxidant stress. Eur J Pharmacol 822: 13-24, 2018.

15. Zieske LR: A perspective on the use of iTRAQ reagent technology for protein complex and profiling studies. J Exp Bot 57: 1501-1508, 2006 
16. Han X,Shao W,Liu Z,Fan S, Yu J, Chen J, Qiao R, Zhou J and Xie P: iTRAQ-based quantitative analysis of hippocampal postsynaptic density-associated proteins in a rat chronic mild stress model of depression. Neuroscience 298: 220-292, 2015.

17. Sharma R, Gowda H, Chavan S, Advani J, Kelkar D, Kumar GS Bhattacharjee M, Chaerkady R, Prasad TS, Pandey A, et al: Proteomic signature of endothelial dysfunction identified in the serum of acute ischemic stroke patients by the itraq-based lc-MS approach. J Proteome Res 14: 2466-2479, 2015.

18. Wang Q, Su X, Jiang X, Dong X, Fan Y, Zhang J, Yu C, Gao W, Shi S, Jiang J, et al: iTRAQ technology-based identification of human peripheral serum proteins associated with depression. Neuroscience 330: 291-325, 2016.

19. Xu DD, Deng DF, Li X, Wei LL, Li YY, Yang XY, Yu W, Wang C, Jiang TT, Li ZJ, et al: Discovery and identification of serum potential biomarkers for pulmonary tuberculosis using iTRAQ-coupled two-dimensional LC-MS/MS. Proteomics 14: 322-331, 2014

20. Mohamed BA, Asif AR, Schnelle M, Qasim M, Khadjeh S, Lbik D, Schott P, Hasenfuss G and Toischer K: Proteomic analysis of short-term preload-induced eccentric cardiac hypertrophy. J Transl Med 14: 149, 2016.

21. Mitra A, Basak T, Ahmad S, Datta K, Datta R, Sengupta S and Sarkar S: Comparative proteome profiling during cardiac hypertrophy and myocardial infarction reveals altered glucose oxidation by differential activation of pyruvate dehydrogenase $\mathrm{e}$ component subunit $\beta$. J Mol Biol 427: 2104-2120, 2015.

22. Chowdhury D, Tangutur AD, Khatua TN, Saxena P, Banerjee SK and Bhadra MP: A proteomic view of isoproterenol induced cardiac hypertrophy: Prohibitin identified as a potential biomarker in rats. J Transl Med 11: 130, 2013.

23. Zamorano-Leon JJ, Modrego J, Mateos-Caceres PJ, Macaya C, Martin-Fernandez B, Miana M, de las Heras N, Cachofeiro V, Lahera V and López-Farré AJ: A proteomic approach to determine changes in proteins involved in the myocardial metabolism in left ventricles of spontaneously hypertensive rats. Cell Physiol Biochem 25: 347-358, 2010.

24. Mesaros C and Blair IA: Mass spectrometry-based approaches to targeted quantitative proteomics in cardiovascular disease. Clin Proteomics 13: 20, 2016.

25. Luo J, Deng ZL, Luo X, Tang N, Song WX, Chen J, Sharff KA, Luu HH, Haydon RC, Kinzler KW, et al: A protocol for rapid generation of recombinant adenoviruses using the AdEasy system. Nat Protoc 2: 1236-1247, 2007.

26. Lopez-Gordo E, Kohlbrenner E, Katz MG and Weber T: AAV vectors for efficient gene delivery to rodent hearts. Methods Mol Biol 1950: 311-332, 2019.

27. Garcia-Olloqui P, Rodriguez-Madoz JR, Di Scala M, Abizanda G, Vales A, Olague C, Iglesias-Garcia O, Larequi E, Aguado-Alvaro LP, Ruiz-Villalba A, et al: Effect of heart ischemia and administration route on biodistribution and transduction efficiency of AAV9 vectors. J Tissue Eng Regen Med: Nov 1, 2019 (Epub ahead of print).

28. Tshori S, Gilon D, Beeri R, Nechushtan H, Kaluzhny D, Pikarsky E and Razin E: Transcription factor MITF regulates cardiac growth and hypertrophy. J Clin Invest 116: 2673-2681, 2006.

29. Chen H, Wang X, Tong M, Wu D, Wu S, Chen J, Wang X, Kang Y, Tang $\mathrm{H}$, Tang $\mathrm{C}$ and Jiang W: Intermedin suppresses pressure overload cardiac hypertrophy through activation of autophagy. PLoS One 8: e64757, 2013.

30. Wang XX, Wang XL, Tong MM, Gan L, Chen H, Wu SS, Chen JX, Li RL, Wu Y, Zhang HY, et al: SIRT6 protects cardiomyocytes against ischemia/reperfusion injury by augmenting FoxO3 $\alpha$-dependent antioxidant defense mechanisms. Basic Res Cardiol 111: 13, 2016

31. Kehat I and Molkentin JD: Molecular pathways underlying cardiac remodeling during pathophysiological stimulation. Circulation 122: 2727-2735, 2010.

32. Zimmer HG: Catecholamine-induced cardiac hypertrophy: Significance of proto-oncogene expression. J Mol Med (Berl) 75 849-859, 1997.

33. Kamalov G, Bhattacharya SK and Weber KT: Congestive heart failure: Where homeostasis begets dyshomeostasis. J Cardiovasc Pharmacol 56: 320-328, 2010.

34. Dunzendorfer S, Schratzberger P, Reinisch N, Kahler CM and Wiedermann CJ: Secretoneurin, a novel neuropeptide, is a potent chemoattractant for human eosinophils. Blood 91: 1527-1532, 1998.
35. Kirchmair R, Marksteiner J, Troger J, Mahata SK, Mahata M, Donnerer J, Amann R, Fischer-Colbrie R, Winkler H and Saria A: Human and rat primary C-fibre afferents store and release secretoneurin, a novel neuropeptide. Eur J Neurosci 6: 861-868, 1994.

36. Schgoer W, Theurl M, Albrecht-Schgoer K, Jonach V, Koller B, Lener D, Franz WM and Kirchmair R: Secretoneurin gene therapy improves blood flow in an ischemia model in type 1 diabetic mice by enhancing therapeutic neovascularization. PLoS One 8: e74029, 2013.

37. Chan CK and Vanhoutte PM: Secretoneurin facilitates endothelium-dependent relaxations in porcine coronary arteries. Am J Physiol Heart Circ Physiol 300: H1159-H1165, 2011.

38. Schgoer W, Theurl M, Jeschke J, Beer AG, Albrecht K, Gander R, Rong S, Vasiljevic D, Egger M, Wolf AM, et al: Gene therapy with the angiogenic cytokine secretoneurin induces therapeutic angiogenesis by a nitric oxide-dependent mechanism. Circ Res 105: 994-1002, 2009.

39. Wang K Master's degree, Chen Z Master's degree, Long L Master's degree, Tao Y Master's degree, Wu Q Master's degree, Xiang M Master's degree, Liang Y Bachelor's degree, Xie X Bachelor's degree, Jiang Y Master's degree, Xiao Z Doctor's degree, et al: iTRAQ-based quantitative proteomic analysis of differentially expressed proteins in chemoresistant nasopharyngeal carcinoma. Cancer Biol Ther 19: 809-824, 2018.

40. Gupta D, Mohammed M, Mekala LP, Chintalapati S and Chintalapati VR: iTRAQ-based quantitative proteomics reveals insights into metabolic and molecular responses of glucose-grown cells of Rubrivivax benzoatilyticus JA2. J Proteomics 194: 49-59, 2019.

41. Luo H, Yao L, Zhang Y and Li R: Liquid chromatography-mass spectrometry-based quantitative proteomics analysis reveals chondroprotective effects of astragaloside IV in interleukin-1 $\beta$-induced SW1353 chondrocyte-like cells. Biomed Pharmacother 91: 796-802, 2017.

42. Ren J, Zhao G, Sun X, Liu H, Jiang P, Chen J, Wu Z, Peng D, Fang $\mathrm{Y}$ and Zhang C: Identification of plasma biomarkers for distinguishing bipolar depression from major depressive disorder by iTRAQ-coupled LC-MS/MS and bioinformatics analysis. Psychoneuroendocrinology 86: 17-24, 2017.

43. Li Z, Huang T, Tang M, Cheng B, Peng Y and Zhang X: iTRAQ-based proteomics reveals key role of gamma-aminobutyric acid (GABA) in regulating drought tolerance in perennial creeping bentgrass (Agrostis stolonifera). Plant Physiol Biochem 145: 216-226, 2019.

44. Chen C, Hao X, Geng Z and Wang Z: ITRAQ-based quantitative proteomic analysis of MG63 in response to HIF-1 $\alpha$ inducers. J Proteomics 211: 103558, 2019.

45. Tian L, You HZ, Wu H, Wei Y, Zheng M, He L, Liu JY, Guo SZ, Zhao Y Zhou RL and Hu X: iTRAQ-based quantitative proteomic analysis provides insight for molecular mechanism of neuroticism. Clin Proteomics 16: 38, 2019.

46. Diguet N, Trammell SAJ, Tannous C, Deloux R, Piquereau J, Mougenot N, Gouge A, Gressette M, Manoury B, Blanc J, et al: Nicotinamide riboside preserves cardiac function in a mouse model of dilated cardiomyopathy. Circulation 137: 2256-2273, 2018.

47. Huang CY, Lee FL, Peng SF, Lin KH, Chen RJ, Ho TJ, Tsai FJ, Padma VV and Kuo WW: HSF1 phosphorylation by ERK/GSK3 suppresses RNF126 to sustain IGF-IIR expression for hypertension-induced cardiomyocyte hypertrophy. J Cell Physiol 233: 979-989, 2018.

48. Wang Y, Zhang Y, Ding G, May HI, Xu J, Gillette TG, Wang H and Wang ZV: Temporal dynamics of cardiac hypertrophic growth in response to pressure overload. Am J Physiol Heart Circ Physiol 313: H1119-H1129, 2017.

49. Kesidis N, Metaxas TI, Vrabas IS, Stefanidis P, Vamvakoudis E, Christoulas K, Mandroukas A, Balasas D and Mandroukas K: Myosin heavy chain isoform distribution in single fibres of bodybuilders. Eur J Appl Physiol 103: 579-583, 2008.

50. Petropoulou E, Soltani M, Firoozabadi AD, Namayandeh SM, Crockford J, Maroofian R and Jamshidi Y: Digenic inheritance of mutations in the cardiac troponin (TNNT2) and cardiac beta myosin heavy chain (MYH7) as the cause of severe dilated cardiomyopathy. Eur J Med Genet 60: 485-488, 2017.

51. Wang L, Zuo L, Hu J, Shao H, Lei C, Qi W, Liu Y, Miao Y, Ma X, Huang CL, et al: Dual LQT1 and HCM phenotypes associated with tetrad heterozygous mutations in KCNQ1, MYH7, MYLK2, and TMEM70 genes in a three-generation Chinese family. Europace 18: 602-609, 2016. 
52. Chugh S, Ouzounian M, Lu Z, Mohamed S, Li W, Bousette N, Liu PP and Gramolini AO: Pilot study identifying myosin heavy chain 7, desmin, insulin-like growth factor 7, and annexin A2 as circulating biomarkers of human heart failure. Proteomics 13: 2324-2334, 2013.

53. Ginsberg HN, Le NA, Goldberg IJ, Gibson JC, Rubinstein A Wang-Iverson P, Norum R and Brown WV: Apolipoprotein B metabolism in subjects with deficiency of apolipoproteins CIII and AI. Evidence that apolipoprotein CIII inhibits catabolism of triglyceride-rich lipoproteins by lipoprotein lipase in vivo. J Clin Invest 78: 1287-1295, 1986.

54. Ooi EM, Barrett PH, Chan DC and Watts GF: Apolipoprotein C-III: Understanding an emerging cardiovascular risk factor. Clin Sci (Lond) 114: 611-624, 2008.

55. Clavey V, Lestavel-Delattre S, Copin C, Bard JM and Fruchart JC: Modulation of lipoprotein B binding to the LDL receptor by exogenous lipids and apolipoproteins CI, CII, CIII, and E. Arterioscler Thromb Vasc Biol 15: 963-971, 1995.
56. Wyler von Ballmoos MC, Haring B and Sacks FM: The risk of cardiovascular events with increased apolipoprotein CIII: A systematic review and meta-analysis. J Clin Lipidol 9: 498-510, 2015.

57. Jorgensen AB, Frikke-Schmidt R, Nordestgaard BG and Tybjaerg-Hansen A: Loss-of-function mutations in APOC3 and risk of ischemic vascular disease. N Engl J Med 371: 32-41, 2014.

58. Luo $\mathrm{M}$ and Peng D: The emerging role of apolipoprotein C-III: Beyond effects on triglyceride metabolism. Lipids Health Dis 15: 184,2016

(i) $\Theta$ This work is licensed under a Creative Commons Attribution-NonCommercial-NoDerivatives 4.0 International (CC BY-NC-ND 4.0) License. 